\title{
A Comparison of Energy Conversion Technologies for Space Nuclear Power Systems
}

\author{
Lee S. Mason ${ }^{1}$ \\ NASA Headquarters, Washington D.C., 20056, U.S.A
}

\begin{abstract}
A key element of space nuclear power systems is the energy conversion subsystem that converts the nuclear heat into electrical power. Nuclear systems provide a favorable option for missions that require long-duration power in hostile space environments where sunlight for solar power is absent or limited. There are two primary nuclear power technology options. Radioisotope Power System (RPS) utilize the natural decay heat from Pu238 to generate electric power levels up to about one kilowatt. Fission Power System (FPS) rely on a sustained fission reaction of $\mathbf{U} 235$ and offer the potential to supply electric power from kilowatts to megawatts. Example missions for nuclear power include Mars science rovers (e.g. Curiosity, Mars 2020), lunar and Mars surface landers, crewed surface outposts, deep space planetary orbiters, Ocean World science landers, and robotic space probes that utilize nuclear electric propulsion (NEP). This paper examines the energy conversion technology options that can be used with RPS and FPS, and provides an assessment of their relative performance.
\end{abstract}

\section{Introduction}

Nuclear systems provide a favorable option for missions that require long-duration power in hostile space environments where sunlight for solar power is absent or limited. Example missions include Mars science rovers (e.g. Curiosity, Mars 2020), lunar and Mars surface landers, crewed surface outposts, deep space planetary orbiters, Ocean World science landers, and robotic space probes that utilize nuclear electric propulsion (NEP). There are two primary nuclear power technology options: Radioisotope Power Systems (RPS) and Fission Power Systems (FPS).

RPS utilize the natural decay heat from Pu238 to generate electric power levels up to about one kilowatt. The NASA Science Mission Directorate (SMD) RPS Program works in partnership with the Department of Energy (DOE) to produce the Pu238 heat sources, supply RPS and related services to flight missions, and develop new power conversion technologies. RPS have been a staple in NASA missions since the 1969 Nimbus III mission with a portfolio that includes Apollo, Pioneer, Viking, Voyager, Cassini, Pluto New Horizons, and most recently, Mars Curiosity. The current class of RPS utilize General Purpose Heat Source (GPHS) modules that supply approximately 250 Watts-thermal at Beginning-of-Life (BOL). Each GPHS module includes four fuel pellets that contain about 0.6 $\mathrm{kg}$ of plutonium-oxide. This fuel form has been in production since the late 1980s when the first GPHS Radioisotope Thermoelectric Generator (RTG) was flown on the Galileo mission. The largest RPS mission ever flown was Cassini (1997) which used three GPHS RTGs to supply nearly 900 Watts at launch using a total of 54 GPHS. The current version is the Multi-Mission RTG (MMRTG) designed to produce about 110 Watts at launch using eight GPHS modules. The MMRTG was first used on Mars Curiosity (Figure 1) and is slated for use on the upcoming Mars 2020 rover.

FPS rely on a sustained fission reaction of U235 and offer the potential to supply electric power from kilowatts to megawatts. The U.S. has flown only one FPS, in 1965. The 500 Watt SNAP 10A (Figure 2) operated for 43 days before a spacecraft malfunction (unrelated to the FPS) caused a premature ending to the mission. NASA and DOE have attempted to develop FPS multiple times since the SNAP 10A, including SP-100 in the late 1980s and Prometheus in the early 2000s. In general, NASA's efforts to develop a space-qualified FPS fell short due to technical complexity, high development costs, and aggressive performance claims. These past attempts were typically accompanied by the need to develop new reactor fuel, structural materials and balance-of-plant components for a system that was bound by mission needs to produce high power at low mass with long operational life. This is a risky combination that undoubtedly contributed to the poor record of success in past programs.

\footnotetext{
${ }^{1}$ Principal Technologist, NASA Space Technology Mission Directorate.
} 

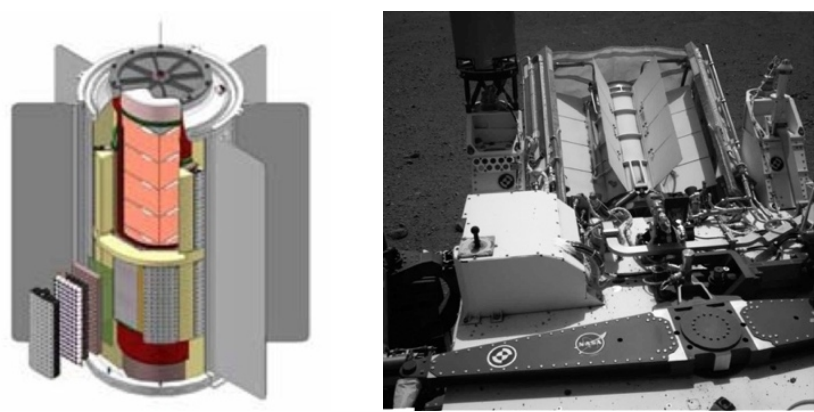

Fig. 1 MMRTG Concept and Installation on Mars Curiosity Rover
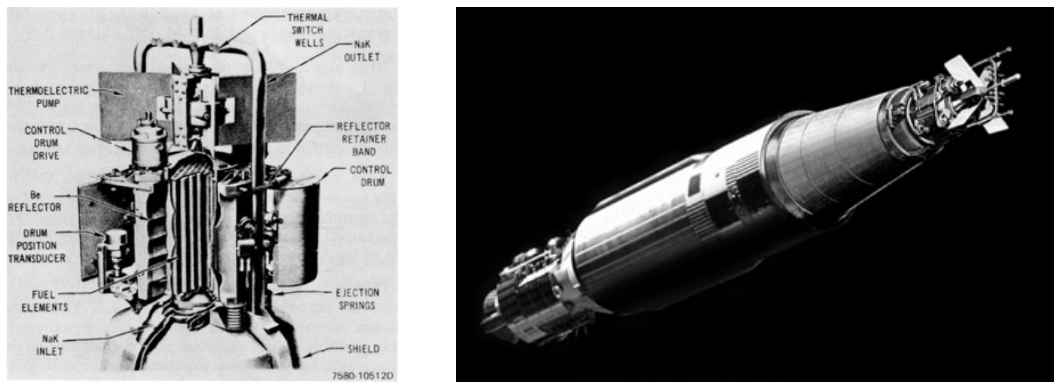

Fig. 2 SNAP-10 Reactor and Flight System Concept
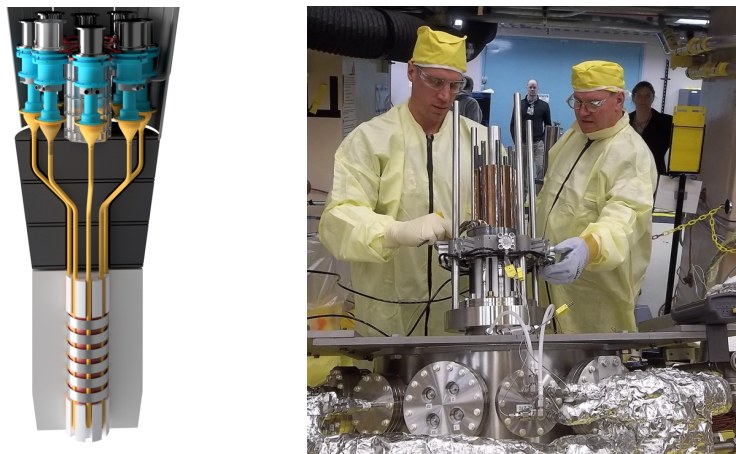

Fig. 3 Kilopower Reactor Concept and Test Unit Assembly

The current space FPS development effort under the NASA Space Technology Mission Directorate (STMD) is Kilopower, which is aimed at FPS that could produce a modest power output between 1 and $10 \mathrm{~kW}$-electric $(\mathrm{kWe})$. The Kilopower Project recently completed a successful nuclear-heated reactor prototype ground test (Figure 3) and is being considered for a possible flight Technology Demonstration Mission in the mid-2020s. The primary mission applications under consideration include lunar and Mars surface power systems. Future versions could be adapted to outer planet science missions including those that use NEP to bring orbiters and landers to the far reaches of the solar system.

While both RPS and FPS are nuclear power systems, they are distinctly different in terms of processing and operations. The U.S. has a very limited supply of the Pu238 used in RPS and the DOE has only recently begun to produce new material after an extended hiatus. The cost and complexity of making Pu238 is significant, and currently depends on NASA funding as the only recognized user. Once the Pu238 fuel is loaded into an RPS at DOE, that system is operational and must be handled carefully through launch due to its elevated temperature and need for thermal control. At launch, the Pu238 has a significant radiological inventory requiring specific safety measures to assure containment should there be a launch accident. After the launch, the RPS has no means of heat source shutdown, so missions must accommodate the constant thermal load. As the Pu238 fuel decays, the thermal output and corresponding RPS electric output power gradually decreases. A distinct advantage of RPS is the benign radiation environment produced by the alpha-emitting Pu238 resulting in minimal radiation effects on equipment or personnel. 
The enriched U235 used in FPS is available from dismantled nuclear weapons and maintained in large quantities by the DOE for purposes that include space reactors. Since NASA is a minor user, there is no funding commitment and no cost for the allocated raw material. However, because the enriched U235 can be used to make weapons, it requires special security measures to safeguard it from proliferation threats. During fabrication and launch processing, the $\mathrm{U} 235$ reactor core is not radioactive nor does it produce heat until the reactor is turned on. To start the reactor, a neutron-absorbing control rod (or rods) is removed from the core to allow the fission reaction to occur. Should there be a launch accident, the U235 core is not a radiation hazard unless the system experiences an inadvertent criticality, which can be avoided by careful design and simple safety systems. After the reactor is started in space, the nuclear reaction and gradual buildup of fission products produce gamma and neutron radiation that requires shielding to protect sensitive equipment and humans. A key discriminator relative to RPS is that the FPS can be stopped and restarted using the control rod, as needed during the mission. The reactor thermal output can also be maintained at a fixed level through occasional (perhaps yearly) control rod adjustments.

\section{Study Methodology}

The premise of this study is to compare energy conversion options based on their power output and specific power $(\mathrm{W} / \mathrm{kg}$ ) assuming three different fixed nuclear heat sources. The heat sources considered are as follows: 1) an array of eight GPHS modules, supplying approximately $2 \mathrm{~kW}$-thermal (kWt),2) the smallest Kilopower reactor, supplying $4.3 \mathrm{kWt}$, and 3) the largest Kilopower reactor, supplying $43 \mathrm{kWt}$. The heat sources will be treated as fixed thermal supplies while accounting for thermal insulation losses and End-of-Mission (EOM) power degradation. System performance generally improves with increasing heat source temperature, so the study will evaluate the benefits of several different hot-end temperatures for each heat source. While GPHS-based heat sources have been shown to operate as high as $1275 \mathrm{~K}$, the Kilopower reactor heat sources are limited to about $1075 \mathrm{~K}$ based on the current cast uranium-molybdenum (UMo) fuel form.

The key variable in determining system power output for a fixed heat source is the conversion cold-end temperature, or more specifically, the converter temperature ratio (Thot/Tcold). The conversion technologies in this study generally behave as thermodynamic heat engines with energy conversion efficiencies that are proportional to their fraction-of-Carnot efficiency. For each heat source and hot-end temperature, an analysis will be performed by varying cold-end temperature to examine the effect on power output, radiator area, and system specific power. In sweeping through the cold-end temperatures for each option, an optimum Tcold occurs as the result of balancing the power produced versus the size of the radiator. The system will have the highest efficiency and produce the maximum power output at the lowest Tcold. However, the low cold-end temperatures result in larger radiators whose area is inversely proportional to the cold-end temperature to the fourth power $\left(\operatorname{Tcold}^{\wedge} 4\right)$.

Determining system mass is a complicated process, which will be greatly simplified in this analysis. The mass of the three heat sources are fixed and taken from published values. A heat source assembly containing 8-GPHS modules weighs about $13 \mathrm{~kg}$, not including structural support or insulation. The smaller $4.3 \mathrm{kWt}$ Kilopower reactor including core, reflector, control rod, and heat pipes weighs about $136 \mathrm{~kg}$ and requires a $148 \mathrm{~kg}$ radiation shield $(284 \mathrm{~kg}$ total mass). The corresponding, larger $43 \mathrm{kWt}$ Kilopower reactor weighs about $235 \mathrm{~kg}$ with a $547 \mathrm{~kg}$ radiation shield (782 $\mathrm{kg}$ total mass). The converter, controller (if needed), housing/heat rejection, thermal insulation and integration masses are derived from historical systems and concepts based on the author's judgement and calculated using appropriate scaling methods. All EOM power values are based on a hypothetical 10-year mission (with 3-year storage for the RPS). The radiator mass is based on Stefan-Boltzmann area calculations with reasonable assumptions on radiator temperature drop, fin effectiveness, thermal emissivity, sink temperature, and aerial density $\left(\mathrm{kg} / \mathrm{m}^{2}\right)$.

\section{Power Conversion Options}

The currently available RPS is the MMRTG containing eight GPHS modules. It uses state-of-the-art PbTe-based ${ }^{2}$ thermoelectric (TE) couples that operate at a hot-end temperature (Thot) of approximately $810 \mathrm{~K}$ and a cold-end (Tcold) of $485 \mathrm{~K}$. The MMRTG weighs approximately $45 \mathrm{~kg}$ and produces 110 Watts at launch $(2.5 \mathrm{~W} / \mathrm{kg})$ in a design that was intended for use in either planetary atmospheres (like Mars) or the vacuum of space. The total generator efficiency is $110 /(8 * 250)$ or $5.5 \%$, but the TE conversion efficiency is more like $6.5 \%$ after accounting for thermal and electrical losses. Given the operating temperatures, the equivalent TE fraction-of-Carnot efficiency is $6.5 \% /(1-$ $485 / 810$ ) or about $16 \%$. Using Curiosity performance data, the output power decreases at a rate of about $4.8 \%$ per year from a combination of fuel decay $(\sim 0.8 \% /$ year $)$ and thermoelectric degradation $(\sim 4 \% /$ year). The source of the

2 The MMRTG uses PbTe "N" Leg and TAGS (Tellurium-Antimony-Germanium-Silver)/PbSnTe "P" Leg thermoelectric couples. For simplicity, this paper uses "PbTe" to designate this combination. 
high thermoelectric degradation is related to material thermal stability and sublimation. For reference, the former vacuum-only GPHS RTG produced about 285 Watts at launch and weighed approximately $56 \mathrm{~kg}(5 \mathrm{~W} / \mathrm{kg})$ while operating at Thot of $1273 \mathrm{~K}$ and Tcold of $573 \mathrm{~K}$. That system used SiGe couples with converter efficiency of about $7.5 \%$, equivalent to $13.5 \%$ fraction-of-Carnot.

The RPS Program is working on advanced TE converters that operate at higher hot-end temperatures and greater efficiencies to increase power output using materials that promise lower degradation. As a first step, the enhanced MMRTG (eMMRTG) uses Skutterudite (SKD) TE couples instead of PbTe. Efficiency and operating temperature can be increased further by adding additional thermoelectric segments to the SKD couples, including Zintl and LaTe compounds (Figure 4). A segmented TE conversion system using this combination could operate at a hot-end temperature of $1075 \mathrm{~K}$ with a Carnot fraction comparable to the PbTe-based systems $(16 \%)$. The new segmented thermoelectric couples are also predicted to have lower degradation rate $(2.5 \% /$ year) compared to MMRTG, resulting in higher EOM power output. With additional segments and/or variants of the Zintl and LaTe materials, the TE converters could a achieve hot-end temperature up to $1275 \mathrm{~K}$, similar to the SiGe couples used in past GPHS RTGs, with better Carnot fraction (16\%) and low predicted degradation (1.9\%/year).

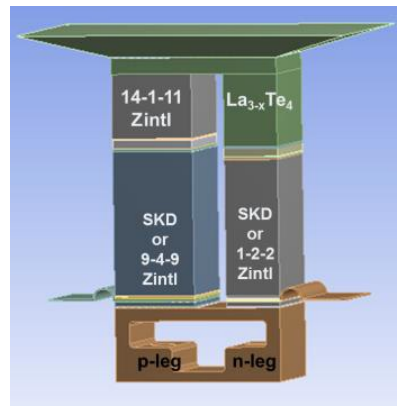

Fig. 4 Representative Segmented Thermoelectric Couple

The application of fixed Carnot fractional efficiencies to represent thermoelectric converter performance is somewhat unorthodox, and there are better methods to use. However, the author has compared results from moresophisticated TE analyses in the literature and found the Carnot method to be simple and accurate.

The RPS Program is also developing power conversion technologies for a dynamic RPS. A recent procurement resulted in four contractor studies exploring free-piston Stirling with gas bearings, free-piston Stirling with flexure bearings, thermoacoustic Stirling and closed Brayton cycle. Dynamic conversion technologies have been under development by NASA for decades but no converter has ever flown in space. The most recent flight development attempt was the Advanced Stirling Radioisotope Generator (ASRG) which utilized two GPHS modules and two freepiston Stirling units (Figure 5) with gas bearings to produce 140 Watts at launch with a system mass of $31 \mathrm{~kg} \mathrm{(4.5}$ $\mathrm{W} / \mathrm{kg}, 28 \%$ generator efficiency). The Stirling converters operated at a hot-end temperature of $1033 \mathrm{~K}$ and cold-end of $313 \mathrm{~K}$ with a converter efficiency of about $38 \%$, after accounting for thermal and electrical losses. The equivalent fraction-of-Carnot for the ASRG converters was 38\%/(1-313/1033) or 54\%. ASRG's ultra-high efficiency may have contributed to its demise as it resulted in converter manufacturing difficulties and test unit reliability issues. Future Stirling converter developments need not push efficiency so hard, but rather focus on simplicity and robustness. A conservative Carnot fraction of $50 \%$ is assumed for the Stirling conversion options in this study. Two hot-end temperatures are considered: $925 \mathrm{~K}$ and $1075 \mathrm{~K}$, representing a low-risk and higher-risk implementation while staying in the class of Ni-based superalloy materials commonly used in recent converter development efforts.

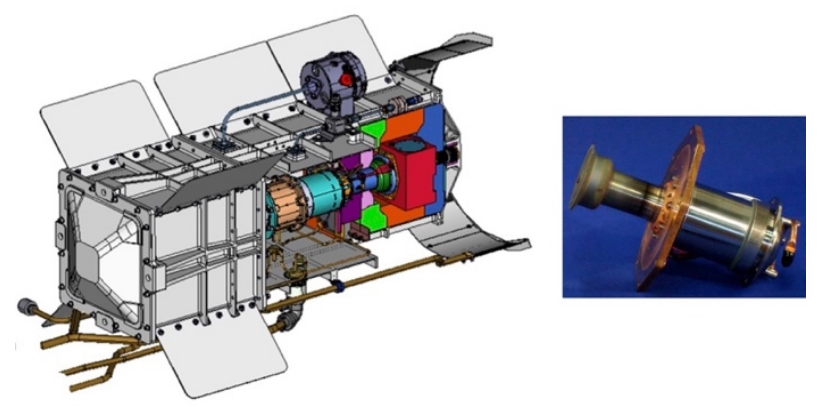

Fig. 5 ASRG Concept and Stirling Converter 
Space Brayton technology has seen many incarnations since the late 1960s including the $1.3 \mathrm{kWe}$ Brayton Isotope Power System (BIPS) and the $2.5 \mathrm{kWe}$ Dynamic Isotope Power System (DIPS). The current effort by the RPS Program is exploring a $0.5 \mathrm{kWe}$-class system with two $100 \%$ redundant converters. In simple terms, the Brayton cycle uses constant pressure heat addition and heat rejection, rather than the constant temperature processes in the Stirling cycle (and the Rankine cycle). This results in a reduced fraction-of-Carnot for space Brayton systems. Stating it differently, Brayton systems require a greater temperature ratio to achieve the same conversion efficiencies as Stirling or Rankine systems. Brayton does offer an advantage in specific power at higher power levels compared to Stirling, due to the high power density of turbomachinery and the use of distributed heat exchangers. In evaluating the past concepts and considering the current one, a conservative fraction-of-Carnot for Brayton is $35 \%$. Like the Stirling options, the Brayton concepts studied here will consider two hot-end temperature values of $925 \mathrm{~K}$ and 1075 $\mathrm{K}$, bounded by the family of possible Ni-based superalloy materials.

Finally, despite it not being part of the RPS dynamic conversion options, the organic Rankine cycle (ORC) is considered here. Space-based ORC systems have received relatively little attention in recent years. In the 1970s, the Kilowatt Isotope Power System (KIPS) utilized the ORC and DOE's Multi-Hundred Watt (MHW) heat source to produce about $1.3 \mathrm{kWe}$ as a competitor to the Brayton-based BIPS (Figure 6). Interestingly, the two concepts were projected to have about the same mass (just over $200 \mathrm{~kg}$ ), but the KIPS version required three heat source assemblies, instead of two for BIPS, and a larger radiator. These same two technologies were pitted against each other again in the 1990s for a $25 \mathrm{kWe}$ solar dynamic power module on Space Station Freedom (SSF). Both the KIPS and SSF ORC systems used toluene working fluid. The primary technical hurdles inhibiting the use of ORCs in space are two-phase fluid management in zero-g and limited hot-end temperature related to toluene decomposition. The maximum hotend temperature for a toluene-based ORC system is about $675 \mathrm{~K}$, which is a blessing for structural materials but a curse for efficiency and radiator area. The advantage of ORC is the high Carnot fraction which is nearly as good as Stirling, and conservatively assumed to be $45 \%$ for this study.

As stated previously for the TE options, the use of fixed Carnot fraction to determine the performance of the dynamic converters is a simplification compared to more sophisticated methods. However, this approach provides a good first-order approximation to compare all the technologies on a relative basis. Regarding degradation, all of the dynamic conversion technologies considered here have non-contacting moving parts (either pistons or rotors) supported by gas and/or mechanical bearings. The resulting converter degradation is negligible, but assumed to be $0.5 \% / \mathrm{yr}$ on top of any heat source degradation.

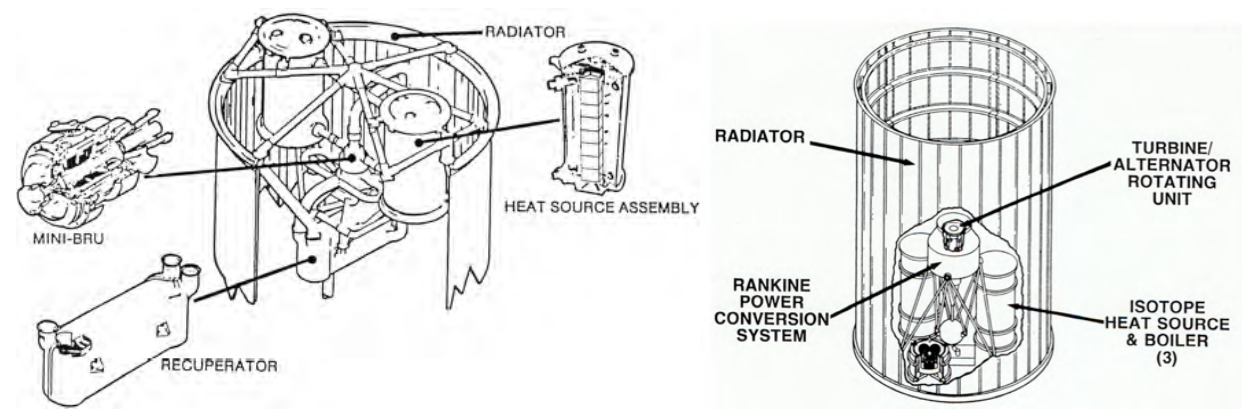

Fig. 6 BIPS (Left) and KIPS (Right) Flight Concepts

\section{RPS Performance Comparisons}

An Excel model was developed to estimate system performance for each heat source and power conversion option described above. The Excel model sweeps through the cold-end temperatures and uses Carnot fraction to estimate power output and the Stefan-Boltzmann equation to estimate radiator area. A system mass is calculated for each design using scaling methods derived from historical systems, and the cold-end temperature that maximizes system specific power $(\mathrm{W} / \mathrm{kg})$ is determined. Separate worksheets were generated for each of the three fixed heat source options considered: 1) $2 \mathrm{kWt}$, 8-GPHS array, 2) $4.3 \mathrm{kWt}$ Kilopower reactor, and 3 ) $43 \mathrm{kWt}$ Kilopower reactor.

The RPS power output and radiator area estimates are presented in Figure 7 assuming the 8-GPHS heat source. The cold-end temperature range considered was 350 to $650 \mathrm{~K}$. The data curves show the relative performance of the TE, ORC, Brayton, and Stirling conversion options assuming a conservative, low hot-end temperature (solid curves) representing the current state-of-the-art and the more advanced, higher hot-end temperature (dashed curves). For the 
TE options, recall that hot-end temperatures of $810 \mathrm{~K}$ (PbTe), $1075 \mathrm{~K}$ (Segmented), and $1275 \mathrm{~K}$ (High Temperature Segmented) are considered. Among the dynamic conversion options, Brayton and Stirling hot-end temperatures of $925 \mathrm{~K}$ and $1075 \mathrm{~K}$ are considered, while the ORC hot-end temperature is $675 \mathrm{~K}$ based on the operating limit of the toluene working fluid. The EOM power output, using the hypothetical 10-year mission duration, ranges from about 50 to $450 \mathrm{We}$, with the highest power output at the lowest cold-end temperature. The radiator curves are very steep due to the pronounced effect of Tcold $\wedge 4$ on rejection area, and range up to about $6.5 \mathrm{~m}^{2}$. The radiator graph also shows lines of constant Tcold to better indicate the sensitivity of area to rejection temperature. Note the high radiator area penalty paid by increasing power output for each of the technology options considered. Most of the benefits are realized at the higher cold-end temperatures before the radiator area curves become asymptotic. While it may seem tempting to choose a low cold-end temperature to maximize efficiency and power output, it has a significant consequence on radiator size.

The RPS system specific power results are presented in Figure 8. Here, and in all subsequent analyses, specific power is defined as the ratio of Beginning-of-Mission (BOM) electric power to total system mass. Each curve covers the range of cold-end temperatures considered and is highlighted by a marker indicating the maximum specific power point. System performance is improved with the higher hot-end temperatures represented by the dashed-curves. For the TE systems, the highest performance is achieved with the $1275 \mathrm{~K}$ hot-end, producing about $100 \mathrm{We} \mathrm{EOM}$ at a specific power of $5.2 \mathrm{~W} / \mathrm{kg}$. The overall highest performing option is the $1075 \mathrm{~K}$ Stirling system, producing about $330 \mathrm{We}$ EOM at a specific power of $5.7 \mathrm{~W} / \mathrm{kg}$. The Brayton and Rankine systems provide higher power output than the TE options, but with lower specific power from 2.5 to $4 \mathrm{~W} / \mathrm{kg}$.
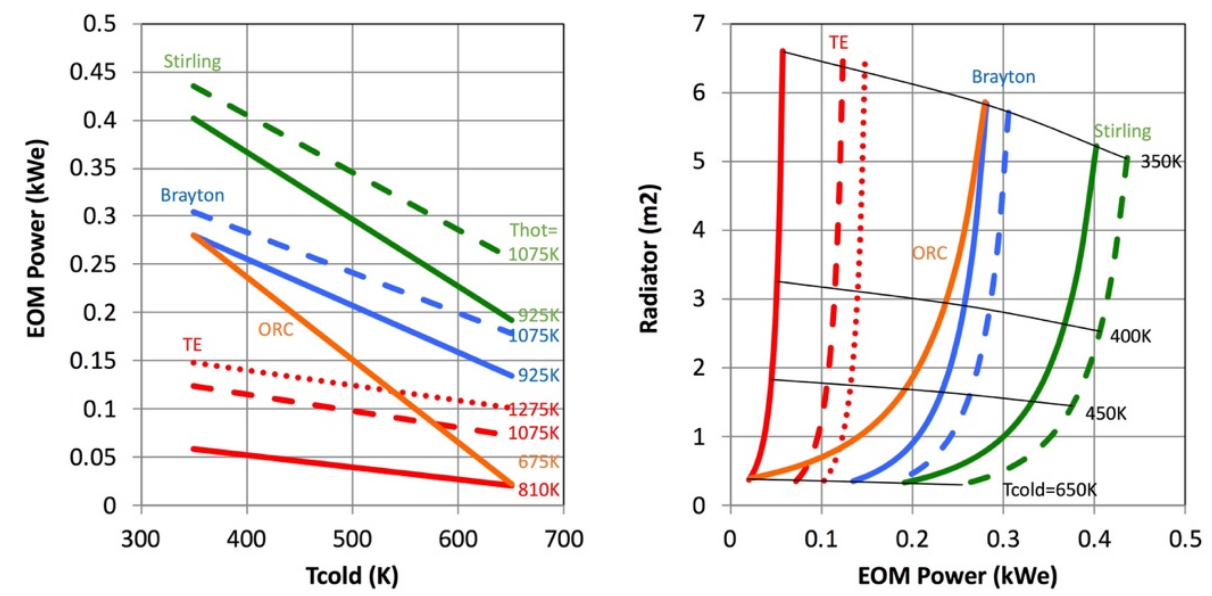

Fig. 7 RPS EOM Power and Radiator Area

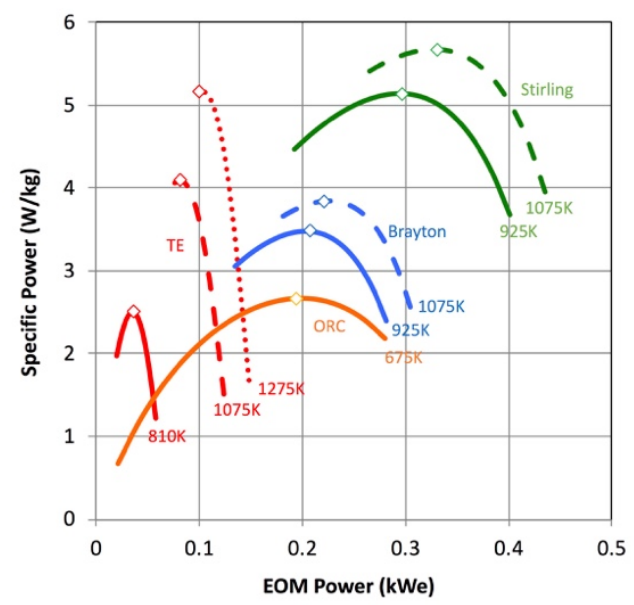

Fig. 8 RPS Specific Power 


\section{FPS Performance Comparisons}

The low-power Kilopower output power and radiator results, assuming the $4.3 \mathrm{kWt}$ reactor, are shown in Figure 9. The range of cold-end temperatures from 275 to $575 \mathrm{~K}$ resulted in EOM power levels between 0.2 and $1.2 \mathrm{kWe}$ and radiator areas up to $35 \mathrm{~m}^{2}$. As before, the solid-curves represent the lower hot-end temperature cases (675 for ORC, $810 \mathrm{~K}$ for TE, and $925 \mathrm{~K}$ for Brayton and Stirling) and the dashed-curves represent the higher hot-end temperature cases (1075 K for TE, Brayton and Stirling). Since the Kilopower reactor cannot achieve a hot-end temperature to accommodate the $1275 \mathrm{~K}$ thermoelectric case, that option is not considered. The radiator area curves exhibit the same steepness observed for the RPS cases. Similar to RPS, there are diminishing benefits in decreasing cold-end temperature to maximize power output. As nuclear power systems approach and exceed the $1 \mathrm{kWe}$ level, the impact of radiator size on system packaging can be significant. A spacecraft or surface mission is much more likely to accommodate a $5 \mathrm{~m}^{2}$ radiator than a $30 \mathrm{~m}^{2}$ radiator. Further, these differences could trigger the need for a more complicated, deployable radiator instead of a simple, fixed one.

The low-power Kilopower specific power results are presented in Figure 10 with the markers indicating the maximum value. As before, both power output and specific power are improved with the higher hot-end temperatures represented by the dashed-curves. The heavier heat source, compared to RPS, leads to less attractive specific power values but introduces the potential for kilowatt-class systems that probably aren't possible with RPS due to the limited Pu238 fuel availability. The best TE system, with a $1075 \mathrm{~K}$ hot-end temperature, produces nearly $350 \mathrm{We}$ EOM at about $1 \mathrm{~W} / \mathrm{kg}$. The best dynamic system is the $1075 \mathrm{~K}$ Stirling option producing $1 \mathrm{kWe}$ EOM at $2.5 \mathrm{~W} / \mathrm{kg}$ (about the same specific power as the current MMRTG). The Brayton and Rankine systems generate around $700 \mathrm{We}$ EOM with specific power ranging from 1.4 to $1.7 \mathrm{~W} / \mathrm{kg}$. It should be noted that that the low-power Kilopower reactor represents the very low end of fission power technology where the minimum, critical mass of the reactor dominates the system. While this power class doesn't necessarily favor a fission solution from a mass basis, using such a system establishes a capability that can scale to higher power levels.

The EOM power and radiator results for the high-power Kilopower options are shown in Figure 11. The range of cold-end temperatures resulted in EOM power levels between 2 and $12 \mathrm{kWe}$ and radiator areas from 10 to $350 \mathrm{~m}^{2}$. By now it should be obvious that the lower cold-end temperatures produce the most power output, but come with a severe penalty on radiator area. Even at the low end, these high power systems are very likely to require a deployable radiator. The specific power results are presented in Figure 12, with values ranging from the $3 \mathrm{~W} / \mathrm{kg}$ for the $3 \mathrm{kWe}$ TE system to $7 \mathrm{~W} / \mathrm{kg}$ for the $10 \mathrm{kWe}$ Stirling system. The Brayton and ORC options produce between 6 and $7 \mathrm{kWe}$ at specific power levels that range between 3 and $5 \mathrm{~W} / \mathrm{kg}$.
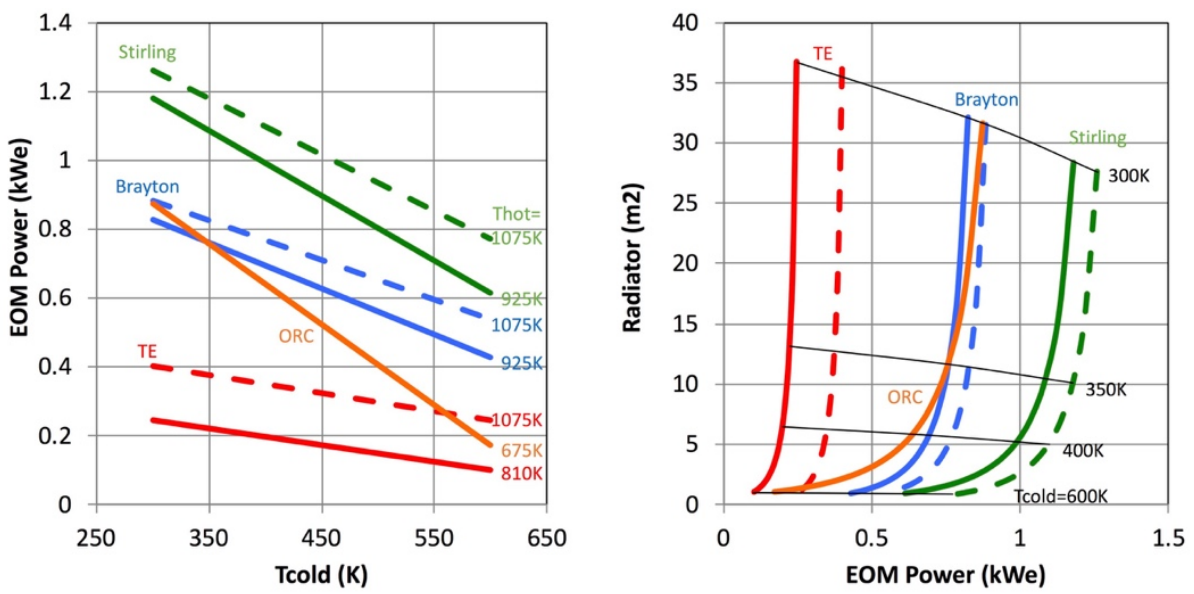

Fig. 9 Small Kilopower EOM Power and Radiator Area 


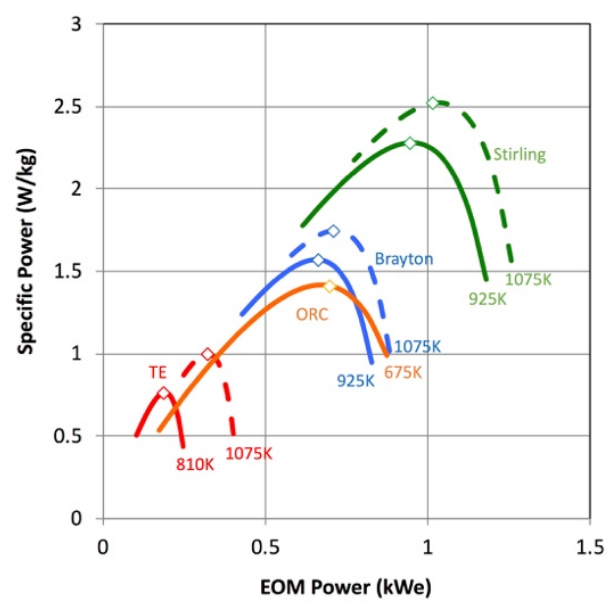

Fig. 10 Small Kilopower Specific Power
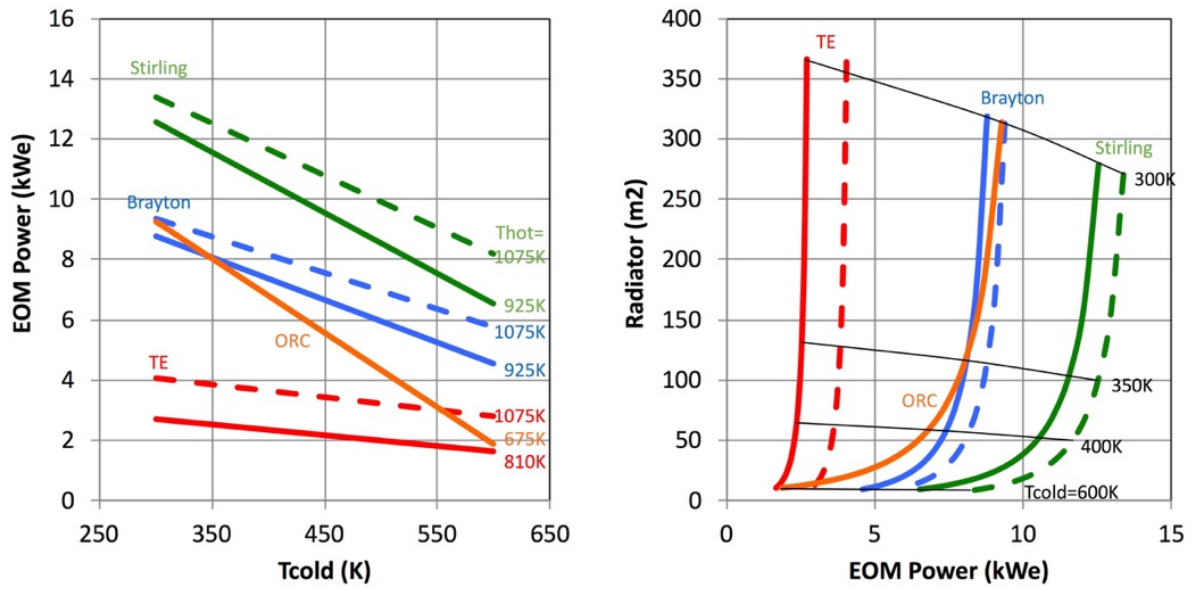

Fig. 11 Large Kilopower EOM Power and Radiator Area

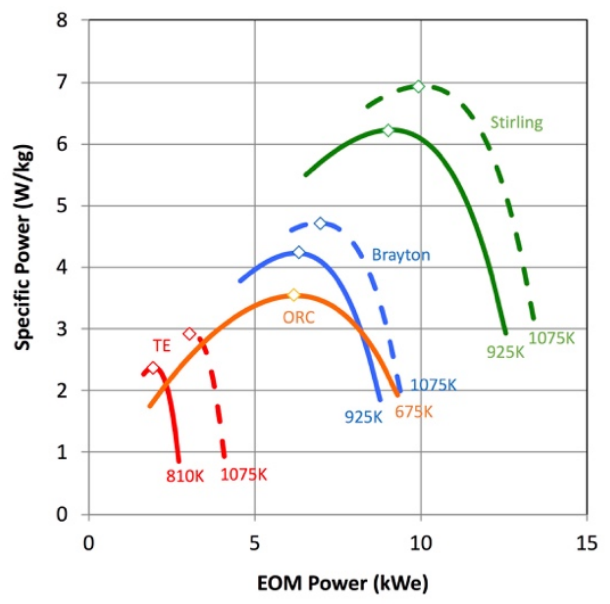

Fig. 12 Large Kilopower Specific Power 


\section{Implications for Future Systems}

This study provides a quantitative assessment of the near-term nuclear heat sources and candidate energy conversion technologies. Figure 13 summarizes the results that include three different heat sources and five energy conversion options. The graph presents the maximum system specific power points plotted against EOM power on a $\log$-scale with the TE options denoted by filled markers and the dynamic options by open markers. These massoptimized systems do not operate at maximum efficiency, but rather strike a balance between power output and radiator area. The RPS options fall on two different exponential trendlines: one for the TE technologies and one for the dynamic technologies. The two FPS options exhibited a different characteristic behavior. For both the small and large Kilopower systems, the TE and dynamic conversion data points lined-up well on single exponential trend lines.

With the 8-GPHS module heat source, TE systems provide the best option for the 100-watt class with specific power between 2.5 and $5 \mathrm{~W} / \mathrm{kg}$. RPS-based dynamic conversion provides similar specific power but offers increased power output, up to $300 \mathrm{We}$ EOM with 8-GPHS. In the power class below about $1 \mathrm{kWe}$, RPS provide a sensible solution. At these power levels, NASA can maintain a steady production of Pu238 to keep up with the mission demand, and eventually adopt dynamic conversion to stretch the fuel inventory further.

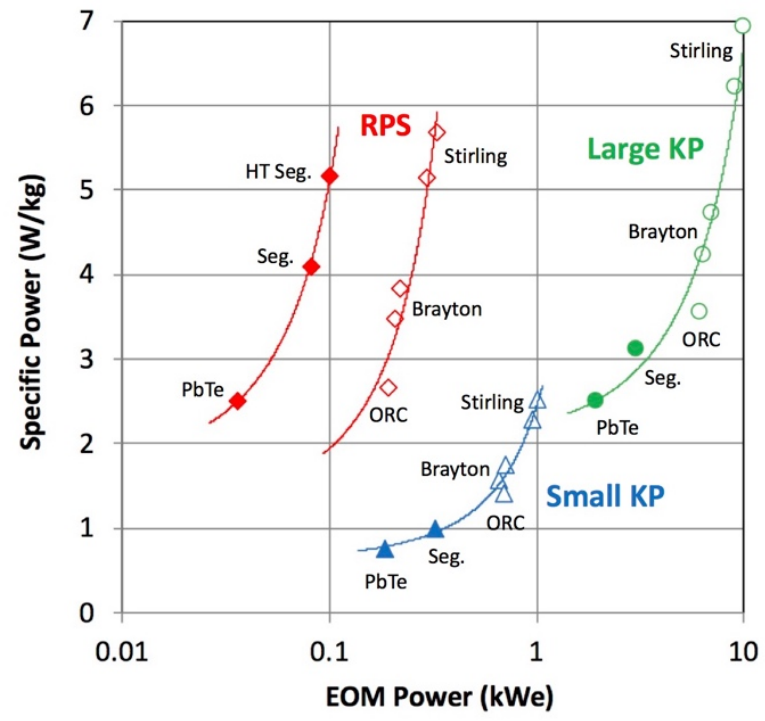

Fig. 13 Overall System Comparison

The small Kilopower systems do not provide a mass advantage relative to RPS, but offer greater power output and don't consume the limited Pu238 supply. The highest-performing small Kilopower systems offer similar specific power to the PbTe RPS at over 25 times the EOM power output. A pragmatic approach to the future of space nuclear power might include the continued use RPS on smaller missions while gradually introducing Kilopower as the mission power requirements exceed $1 \mathrm{kWe}$. An early flight demonstration of a small Kilopower unit could be used to gain experience and confidence in fission technology for larger Kilopower systems that will be needed on later human missions. The larger Kilopower class can provide up to $10 \mathrm{kWe}$, with specific power that exceeds the best RPS options by over $20 \%$.

This study shows Stirling to be the best conversion technology from both an EOM power output and specific power perspective, across all three heat sources studied. The results are strongly influenced by Stirling's high fractionof-Carnot efficiency which leads to high power output with relatively low radiator area. While TE systems suffer from the lowest efficiency and highest power degradation rates, they are the only conversion technology with space heritage and a proven record of mission reliability. Brayton and Rankine performance falls between TE and Stirling in this power regime. Previous studies suggest their best application is for power systems beyond $10 \mathrm{kWe}$. All the conversion technologies benefit by higher hot-end operating temperatures. The TE systems benefit the greatest with the high temperature (HT) segmented option providing nearly three times the power and twice the specific power of the PbTe option. The $1075 \mathrm{~K}$ segmented TE systems offer significant performance advantages relative to the $810 \mathrm{~K}$ systems across all the heat sources. Increasing the hot-end of the Stirling and Brayton systems from $925 \mathrm{~K}$ to $1075 \mathrm{~K}$ provides about a $10 \%$ increase in power and specific power. 


\section{Conclusion}

RPS have been used successfully in space for over 50 years and several upcoming NASA missions, including the Mars 2020 rover and the proposed New Frontiers' Titan Dragonfly rotorcraft, will benefit by their use. The RPS Program is pursuing the Next Generation RTG that provides modularity and promises reduced degradation for deep space missions. Also under development by the RPS Program is a new class of dynamic power converters with robustness and resiliency in mind. The future is bright for nuclear power with the success of the Kilopower test, opening the real possibility for near-term fission power systems on the moon, Mars and beyond. Nuclear fission is an essential building block if we intend to sustain a human presence on other planetary surfaces and rely on local resources to reduce our dependence on earth. In order to realize this future, NASA must continue to invest in nuclear systems with particular attention to the energy conversion technologies that achieve high efficiency, low system mass, and long service life.

\section{References}

[1] Bennett, G. L., et al., "Mission of Daring: The General-Purpose Heat Source Radioisotope Thermoelectric Generator," 4th International Energy Conversion Engineering Conference and Exhibit (IECEC), 26-29 June 2006, San Diego, CA, AIAA 2006-4096.

[2] NASA Multi-Mission Radioisotope Thermoelectric Generator (MMRTG) Fact Sheet, https://rps.nasa.gov/resources/58/multimission-radioisotope-thermoelectric-generator-mmrtg/ [retrieved 18 June 2018].

[3] NASA Enhanced Multi-Mission Radioisotope Thermoelectric Generator (eMMRTG) Concept Fact Sheet, https://rps.nasa.gov/resources/56/enhanced-multi-mission-radioisotope-thermoelectric-generator-emmrtg-concept/ [retrieved 18 June 2018].

[4] NASA Advanced Stirling Radioisotope Generator Fact Sheet, https://rps.nasa.gov/resources/65/advanced-stirlingradioisotope-generator-asrg/ [retrieved 18 June 2018].

[5] Woerner, D. F., "Next Generation RTGs for NASA," AIAA Propulsion and Energy Forum, 10-12 July 2017, Atlanta, GA, AIAA 2017-4612.

[6] Lewandowski, E. J., "Testing of the Advanced Stirling Radioisotope Generator Engineering Unit at NASA Glenn Research Center," NASA/TM-2013-217854.

[7] Wong, W. A., Wilson, S. D., and Collins, J., "Advanced Stirling Convertor Development for NASA Radioisotope Power Systems,"NASA/TM-2015-218461.

[8] AiResearch Manufacturing Company of Arizona, "Brayton Isotope Power System, Phase I Final Report," 31-2919, 28 July 1978, Department of Energy Contract EY-76-C-03-1123.

[9] Sundstrand Energy Systems, "Final Phase I Report, Organic Rankine Kilowatt Isotope Power System" COO-4299-032, 15 July 1978, Department of Energy Contract EN-77-C-02-4299.

[10] McNutt, R. L., and Ostdiek, P. H., "Nuclear Power Assessment Study Final Report," The Johns Hopkins University Applied Physics Laboratory, 4 February 2015, NASA Contract NNN06AA01C.

[11] Mason, L., et al., "A Small Fission Power System for NASA Planetary Science Missions," NASA/TM-2011-217099.

[12] Mason, L., and Carmichael, C., "A Small Fission Power System With Stirling Power Conversion for NASA Science Missions," NASA/TM-2011-217204.

[13] Gibson, M. A., et al., "Development of NASA's Small Fission Power System for Science and Human Exploration," NASA/TM-2015-218460.

[14] Gibson, M. A., Oleson, S. R., Poston, D. I., and McClure, P., "NASA's Kilopower Reactor Development and the Path to Higher Power Missions," 2017 IEEE Aerospace Conference, 4-11 March 2017, Big Sky, MT.

[15] Palac, D. T., Gibson, M. A., Mason, L. S., McClure, P., and Robinson, R. C., "Kilopower KRUSTY Fission Power Demonstration Update," Nuclear and Emerging Technologies for Space 2018, 26 February 2018, Las Vegas, NV. 